\title{
PENGARUH MINYAK JAGUNG (CORN OIL) TERHADAP PENURUNAN KADAR KOLESTEROL LDL PADA TIKUS YANG DIINDUKSI PAKAN TINGGI LEMAK
}

Geby Khomaro Putri ${ }^{1}$, Adrian Suhendra ${ }^{2}$, Teresa Liliana Wargasetia ${ }^{3}$

${ }^{1}$ Fakultas Kedokteran Universitas Kristen Maranatha

${ }^{2}$ Bagian Patologi Klinik, Fakultas Kedokteran Universitas Kristen Maranatha

${ }^{3}$ Bagian Biologi, Fakultas Kedokteran Universitas Kristen Maranatha

Korespondensi: gebykhomaro@gmail.com

\begin{abstract}
ABSTRAK
Latar Belakang: Penyakit jantung koroner (PJK) merupakan penyebab kematian nomor satu di dunia. Etiologi PJK tersering adalah aterosklerosis dengan dislipidemia sebagai salah satu faktor risiko. Berbagai upaya dilakukan untuk menurunkan kadar kolesterol LDL untuk penanganan dislipidemia.

Tujuan Penelitian: Penelitian ini untuk mengetahui efek minyak jagung dalam menurunkan kadar LDL darah pada tikus yang diinduksi pakan tinggi lemak.

Metode Penelitian: Desain penelitian ini adalah eksperimental murni dengan rancangan acak lengkap. Dua puluh lima tikus diberi pakan tinggi lemak selama 7 hari, kemudian dibagi ke dalam 5 kelompok perlakuan yaitu kontrol negatif $(\mathrm{KN})$ yang diberi pakan tinggi lemak (PTL) dan akuades, kontrol positif (KP) yang diberi PTL dan simvastatin dosis $0,9 \mathrm{mg} / \mathrm{kgBB} /$ hari, P1 (PTL dan minyak jagung 0,08 ml), P2 (PTL dan minyak jagung 0,15 ml), dan P3 (PTL dan minyak jagung 0,30 ml). Perlakuan diberikan selama 28 hari. Variabel respons adalah kadar LDL. Analisis data menggunakan ANOVA satu arah, dilanjutkan Tukey HSD dengan $\mathrm{a}=0,05$.

Hasil Penelitian: Kelompok P3 dan P2 berbeda bermakna dengan KN $(p=0,000$ dan $p=0,019)$. P2 dan P3 berbeda bermakna dengan KP ( $p=0,000$ dan $\mathrm{p}=0,000)$. P1 berbeda tidak bermakna dengan $\mathrm{KN}(\mathrm{p}=0,554)$.

Kesimpulan: Minyak jagung dapat menurunkan kadar kolesterol LDL pada dosis $0,15 \mathrm{ml} /$ ekor/hari dan $0,30 \mathrm{ml} /$ ekor/hari tetapi tidak sebaik simvastatin.
\end{abstract}

Kata Kunci: minyak jagung, dislipidemia, LDL, simvastatin 


\title{
THE EFFECT OF CORN OIL TO DECREASE LDL CHOLESTEROL LEVELS IN RATS INDUCED HIGH CHOLESTEROL DIET
}

\author{
Geby Khomaro Putri ${ }^{1}$, Adrian Suhendra ${ }^{2}$, Teresa Liliana Wargasetia ${ }^{3}$ \\ ${ }^{1}$ Medical Faculty of Maranatha Christian University \\ ${ }^{2}$ Bagian Patologi Klinik, Medical Faculty of Matanatha Christian University \\ ${ }^{3}$ Bagian Biologi, Medical Faculty of Matanatha Christian University
}

Correspondence: gebykhomaro@gmail.com

\begin{abstract}
Background: Coronary heart disease (CHD) is the number one cause of death in the world. The most common etiology of CHD is atherosclerosis with dyslipidemia as one risk factor. Various attempts were made to lower LDL cholesterol levels for the treatment of dyslipidemia.

Research Purpose: This research was to study the effect of corn oil in lowering blood LDL levels in rats induced with high-cholesterol diet.

Research Methodology: The research design was a simple experimental with a completely randomized design. Twenty-five Wistar rats were fed high fat diet for 7 days, then were divided into 5 groups, namely the negative control (KN) which were fed high-cholesterol and distilled water, positive control (KP) were fed highcholesterol and $0.9 \mathrm{mg} / \mathrm{kg} /$ day simvastatin, $P 1$ (high-cholesterol diet and $0.08 \mathrm{ml}$ corn oil), P2 (high-cholesterol diet and $0.15 \mathrm{ml}$ corn oil), and P3 (high-cholesterol diet and $0.30 \mathrm{ml}$ corn oil). Treatment was given for 28 days. The response variable is the LDL levels. Analysis data using one-way ANOVA, followed by Tukey HSD with $a=0.05$.

Results: $P 3$ and $P 2$ groups were significantly different with $K N(p=0.000$ and $p=0.019) . P 2$ and $P 3$ were significantly different with $K P(p=0.000$ and $p=0.000) . P 1$ was not significantly different with $K N(p=0.554)$.

Conclusion: Corn oil can reduce LDL levels in dose of $0.15 \mathrm{ml} / \mathrm{rat} /$ day and $0.30 \mathrm{ml} / \mathrm{rat} / \mathrm{day}$, but not as good as simvastatin.
\end{abstract}

Keywords: corn oil, dyslipidemia, LDL, simvastatin 


\section{PENDAHULUAN}

Penyakit kardiovaskuler adalah penyakit yang disebabkan gangguan fungsi jantung dan pembuluh darah. ${ }^{1}$ Ada berbagai macam penyakit kardiovaskuler tetapi yang paling umum dan banyak terjadi adalah penyakit jantung koroner (PJK). Etiologi PJK tersering adalah akibat aterosklerosis. Faktor risiko PJK meliputi faktor yang tidak dapat dimodifikasi seperti genetik, usia, jenis kelamin serta faktor yang dapat dimodifikasi seperti hipertensi, dislipidemia, kurang aktivitas fisik, obesitas, dan merokok. ${ }^{2}$

Penyakit kardiovaskuler adalah penyebab kematian nomor satu di dunia. Diperkirakan sekitar 17,5 juta orang per tahun meninggal akibat penyakit kardiovaskular, yaitu sekitar 31\% dari kematian di dunia. Dari total kematian yang ada, sekitar 7,4 juta orang meninggal per tahun akibat PJK. Lebih dari 3/4 kematian akibat penyakit kardiovaskuler berasal dari negara berpenghasilan rendah sampai menengah. Kematian yang disebabkan oleh penyakit kardiovaskuler, terutama PJK dan stroke diperkirakan akan terus meningkat mencapai 23,3 juta kematian per tahun pada tahun 2030. ${ }^{1}$

Prevalensi PJK di Indonesia berdasarkan diagnosis dokter sebesar $0,5 \%$ atau diperkirakan sekitar 883.447 orang dengan estimasi jumlah penderita PJK terbanyak terdapat di propinsi Jawa Barat sebanyak 160.812 orang $(0,5 \%)$. Jumlah penderita penyakit stroke di Indonesia berdasarkan diagnosis tenaga kesehatan (Nakes) diperkirakan sebanyak 1.236 .825 orang $(7,0 \%)$ dan propinsi Jawa Barat memiliki estimasi jumlah penderita terbanyak yaitu sebanyak 238.001 orang $\left(7,4 \%\right.$ o) ${ }^{3}$

Salah satu faktor risiko PJK yang dapat dimodifikasi adalah kadar kolesterol darah yang tinggi atau dislipidemia. ${ }^{2}$ Ada dua jenis kolesterol yang paling berpengaruh terhadap risiko PJK yaitu low-density lipoprotein (LDL) dan high-density lipoprotein (HDL).

Diet adalah salah satu bentuk usaha preventif dan penatalaksanaan penyakit kardiovaskuler. Salah satu diet yang dapat dilakukan adalah dengan mengonsumsi minyak jagung (corn oil). Minyak jagung sebagai sumber energi (kalori) yang mudah dicerna, asam lemak esensial, vitamin $\mathrm{E}$, dan kaya akan polyunsaturated fatty acids (PUFA) yang dapat membantu regulasi kadar kolesterol darah dan menurunkan tekanan darah. Minyak jagung mengandung asam linoleat yang merupakan asam lemak essensial yang tidak dapat diproduksi oleh tubuh. ${ }^{4}$

Di Indonesia sendiri penggunaan minyak jagung masih tergolong sedikit karena masyarakat lebih sering menggunakan minyak kelapa sawit padahal minyak jagung dapat dijadikan pilihan alternatif yang lebih baik. Minyak jagung merupakan alternatif pengganti minyak yang mempunyai berbagai kandungan yang berefek baik terhadap kesehatan terutama dalam menurunkan kolesterol dan risiko serangan jantung koroner. ${ }^{5}$

Maka dari itu penulis melakukan penelitian terhadap minyak jagung dan dampaknya dalam menurunkan LDL pada hewan coba.

\section{METODE PENELITIAN}

Desain penelitian ini adalah
eksperimental murni dengan rancangan acak lengkap pada 25 ekor tikus jantan galur Wistar. Hewan coba dibagi ke dalam lima kelompok perlakuan, masing-masing kelompok terdiri dari lima hewan coba.

Alat yang digunakan pada penelitian ini adalah kandang tikus 
dan kawat penahan tikus, botol minuman, panci dan pengaduk, kompor, blender, timbangan analitik, pipet Pasteur, spidol, mikropipet, sonde oral, tabung Eppendorf, alat untuk menghitung kadar kolesterol LDL yaitu Cobas Roche C-311. Bahan yang digunakan pada penelitian ini adalah minyak jagung dari pasar swalayan, propiltiourasil $0,01 \%$ di dalam air minum, simvastatin, bahan pakan tinggi lemak. Objek penelitian adalah tikus jantan galur Wistar (Rattus norvegicus L.) usia 8-12 minggu, dengan berat badan (BB) 200-250 gram sebanyak 25 ekor yang diperoleh dari Laboratorium Farmakologi dan Terapi Rumah Sakit Hasan Sadikin.

Tikus jantan galur Wistar usia 8-12 minggu dengan BB 200-250 gram diaklimatisasi selama satu minggu agar dapat menyesuaikan diri dengan lingkungannya. Setelah diaklimatisasi selanjutnya tikus diinduksi dislipidemia dengan pakan tinggi lemak (PTL) sebanyak 50 gram/ekor/hari dan propiltiourasil $0,01 \%$ di dalam air minum selama 7 hari. Pada tahap ini dilakukan pengamatan terhadap keadaan umum dan penimbangan badan setiap hari.

Tikus-tikus dikelompokkan dan diberi perlakuan sebagai berikut: Kelompok kontrol negatif (KN): tikustikus dalam kelompok ini diberi PTL saja; Kelompok kontrol positif (KP): tikus-tikus dalam kelompok ini diberi PTL simvastatin $0,9 \mathrm{mg} / \mathrm{kgBB} / \mathrm{hari}$; Kelompok 1: tikus-tikus dalam kelompok ini diberi PTL corn oil p.o. sebanyak 0,08 $\mathrm{ml} /$ ekor/hari; Kelompok 2: tikus-tikus dalam kelompok ini diberi PTL corn oil p.o. sebanyak $0,15 \mathrm{ml} / \mathrm{ekor} / \mathrm{hari}$; Kelompok 3: tikus-tikus dalam kelompok ini diberi PTL (PTU?)+ corn oil p.o. sebanyak 0,30 ml/ekor/hari. Setelah 28 hari profil lipid LDL dari 25 ekor tikus diperiksa dengan mengambil darah tikus melalui pungsi vena ekor tikus.

Data yang diukur kadar kolesterol LDL pasca pemberian minyak jagung. Analisis data persentase penurunan kadar kolesterol LDL menggunakan uji analisis varian (ANOVA) satu arah menggunakan bantuan perangkat lunak SPSS 22. Bila terdapat perbedaan di antara minimal satu pasang kelompok perlakuan, maka uji dilanjutkan menggunakan uji Tukey HSD dengan a=0,05.

\section{HASIL PENELITIAN}

Pada penelitian ini didapatkan hasil penurunan kadar kolesterol LDL terbesar adalah kelompok KP (PTL+simvastatin 0,9 mg/kgBB/hari) sebesar 21,55\% diikuti dengan penurunan kadar kolesterol LDL kelompok P3 (PTL+ minyak jagung p.o. $\quad 0,30 \mathrm{ml} /$ ekor/hari) sebesar 13,30\%, kelompok P2 (PTL+ minyak jagung p.o. $0,15 \mathrm{ml} /$ ekor/hari) sebesar 7,36\%, kelompok P1 (PTL+ minyak jagung p.o. 0,08 $\mathrm{ml} /$ ekor/hari) sebesar 4,44\%, dan kelompok KN (PTL saja) sebesar $2,53 \%$. Grafik rerata persentase penurunan kadar kolesterol LDL pada kelima kelompok perlakuan disajikan pada Gambar 1. 


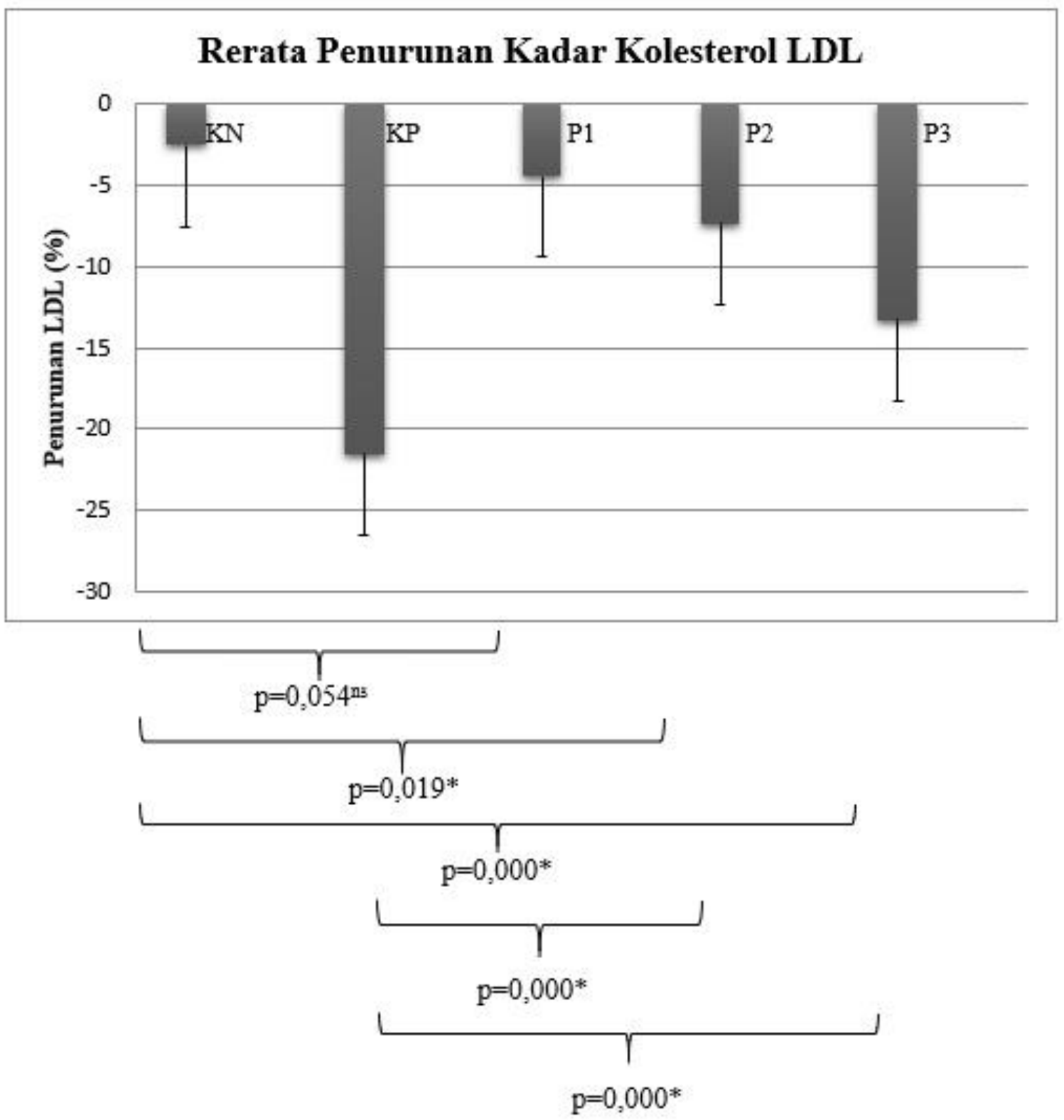

Gambar 1. Rerata Penurunan Kadar Kolesterol LDL

Keterangan:

KN (Kontrol Negatif) : diberikan pakan tinggi lemak + akuades

KP (Kontrol Positif) : diberikan pakan tinggi lemak + simvastatin 0,9 $\mathrm{mg} / \mathrm{kgBB} /$ hari

P1 (Perlakuan 1) : diberikan pakan tinggi lemak + minyak jagung p.o. sebanyak 0,08 $\mathrm{ml} /$ ekor/hari

P2 (Perlakuan 2) : diberikan pakan tinggi lemak + minyak jagung p.o. sebanyak 0,15 ml/ekor/hari

P3 (Perlakuan 3) : diberikan pakan tinggi lemak + minyak jagung p.o. sebanyak $0,30 \mathrm{ml} / \mathrm{ekor} /$ hari

ns

perbedaan tidak bermakna (non-significant)

*

: perbedaan bermakna dengan $p<0,05$ (significant) 
Pengelolaan data persentase penurunan kadar kolesterol LDL menggunakan uji ANOVA satu arah dengan tingkat kemaknaan (Level of significancy) $\mathrm{a}=0,05$. Sebelum dilakukan uji ANOVA satu arah, dilakukan uji homogenitas (Levene test) untuk mengetahui apakah data memiliki varian yang sama atau tidak.

Uji homogenitas (Levene test) didapatkan $\mathrm{p}=0,640$ sehingga variasi dalam masing-masing kelompok adalah homogen sehingga analisis bisa dilanjutkan dengan uji ANOVA satu arah. Hasil uji ANOVA satu arah didapatkan Fhitung $(96,559)>$ Ftabel $(2,87)$ serta $p=0,000$ yang menunjukkan terdapat perbedaan persentase penurunan kadar kolesterol LDL yang bermakna antar minimal sepasang kelompok perlakuan.

Dari Gambar 1 dapat dilihat adanya perbedaan yang bermakna bila kelompok KN dibandingkan dengan kelompok P2 $(p=0,019)$ dan kelompok P3 $(p=0,000)$. Pada kelompok KP jika dibandingkan dengan kelompok P2 (0,15 $\mathrm{ml}$ /ekor/hari), dan kelompok P3 $(0,30 \mathrm{ml} /$ ekor/hari) didapatkan perbedaan bermakna $(p=0,000)$. Pada kelompok KN jika dibandingkan dengan kelompok P1 didapatkan perbedaan tidak bermakna $(p=0,054)$. Antara kelompok P1 dan kelompok P3 didapatkan perbedaan bermakna $(\mathrm{p}=0,000)$. Antara kelompok P2 dan kelompok P3 juga didapatkan perbedaan bermakna $(p=0,000)$.

\section{PEMBAHASAN}

Berdasarkan hasil penelitian pada Gambar 1 terlihat bahwa potensi minyak jagung dalam menurunkan kadar kolesterol LDL paling baik adalah dosis P3 $(0,30$ $\mathrm{ml} /$ ekor/hari) sebesar 13,30\% diikuti oleh dosis P2 $(0,15 \mathrm{ml} /$ ekor/hari) sebesar $7,36 \%$ walaupun belum sebaik kelompok KP (simvastatin) dengan rerata penurunan kadar kolesterol LDL sebesar 21,55\%. Jika kelompok KN dibandingkan dengan dosis P1 dengan persentase rata-rata penurunan kadar kolesterol LDL $4,44 \%$ didapatkan hasil tidak bermakna pada data statistik. Hal ini menunjukkan bahwa minyak jagung dapat menurunkan kadar kolesterol LDL pada dosis tertentu walaupun belum sebaik simvastatin yaitu pada dosis 0,15 ml/ekor/hari dan 0,30 $\mathrm{ml} /$ ekor/hari.

Penelitian serupa juga pernah dilakukan oleh Kawakami et al. pada tahun 2015 dengan menggunakan minyak jagung corn oil masingmasing sebanyak $10 \mathrm{~g} /$ hari pada lelaki di Jepang dan didapatkan penurunan kadar kolesterol LDL yang signifikan pada minggu ke-4 sebesar $5,83 \%{ }^{6}$ Selain itu, penelitian oleh Ostlund et al. pada tahun 2002 didapatkan bahwa $150 \mathrm{mg}$ phytosterols yang terdapat dalam minyak jagung dapat menurunkan absorbsi kolesterol sebesar $12,1 \pm 3,7 \% .{ }^{7}$ Penelitian lainnya juga dilakukan oleh Ander et al. pada tahun 2010 menunjukkan konsumsi minyak ikan (fish oil) dengan dosis $1,65 \mathrm{~g} /$ hari yang mengandung PUFA dapat memperlambat progres aterosklerosis dan mempercepat regresi plak aterosklerotik. ${ }^{8}$

Minyak jagung diduga dapat menurunkan kadar kolesterol LDL karena mengandung PUFA dan phytosterols. Polyunsaturated fatty acid dapat mengubah profil lipid dengan cara memodifikasi komposisi kolesterol LDL yaitu dengan meningkatkan apolipoprotein B dan menurunkan kadar lipoprotein sehingga terbentuk molekul kurang aterogenik. Polyunsaturated fatty acid juga dapat memodulasi produksi dan pelepasan NO yang berfungsi mengatur relaksasi vaskular dan menghambat proses aterosklerosis dengan cara menghambat agregasi trombosit, adesi monosit, serta 
proliferasi dan migrasi vaskular otot polos (PMVOP). ${ }^{8}$ Polyunsaturated fatty acid juga mengaktifkan PPAR terutama PPAR-a yang tampaknya berperan dalam meningkatkan oksidasi asam lemak ke hati dan menurunkan sekresi triasilgliserol. ${ }^{9}$

Adanya kandungan phytosterols yang tinggi diduga dapat mengurangi penyerapan kolesterol dalam usus baik kolesterol endogen maupun eksogen dengan beberapa mekanisme yaitu: (1) Kolesterol yang memasuki garam empedu dan melewati usus dan peredaran darah diserap oleh phytosterols, (2) Kolesterol terutama kolesterol LDL yang berada dalam usus yang sudah separuh terlarut diubah menjadi tidak terlarut sehingga tidak beredar di dalam darah. 8,10

\section{KESIMPULAN}

Minyak jagung menurunkan kadar kolesterol LDL pada tikus yang dinduksi pakan tinggi lemak. Minyak jagung menurunkan kadar kolesterol pada dosis $0,15 \mathrm{ml} /$ ekor/hari dan dosis $0,30 \mathrm{ml} /$ ekor/hari tetapi tidak sebaik simvastatin.

\section{DAFTAR PUSTAKA}

1. World Health Organization (WHO). 2015.Cardiovascular Diseases (CVDs). http://www. who.int/mediacentre/factsheets / fs317/en/. 24 Januari 2016.

2. Copstead L E, \& Banasik J L. Pathophysiology (3 ${ }^{\text {rd }}$ edition). Philadelphia, USA: Elsevier Saunders. 2005.

3. Kementrian Kesehatan RI. Infodatin Situasi Kesehatan Jantung. 2014.
4. Corn Refiners Association. Corn Oil. https://corn.org/wpcontent/uploads/2009/12/Corn Oil.pdf. 25 Agustus 2016

5. Dwiputra $\dagger$ D, Jagat A $N$, Wulandari F K, Prakarsa A S, Puspaningrum D A, \& Islamiyah F. Minyak Jagung Alternatif Pengganti Minyak yang Sehat. Jurnal Aplikasi Teknologi Pangan, 2015. 4(2): v-vi.

6. Kawakami $\dagger$ Y, YamanakaOkumura $\dagger$ H, Naniwa-Kuroki $\dagger$ Y, Sakuma M., Taketani Y, \& Takeda E. 2015. Flaxseed oil intake reduces serum small dense low-density lipoprotein concentrations in Japanese men: a randomized, double blind, crossover study. Nutrition Journal , 1-9.

7. Ostlund Jr R, Racette S, Okeke A, $\&$ Stenson W. Phytosterols that are naturally present in commercial corn oil significantly reduce cholesterol absorption in humans. Am J Clin Nutr, 2002.75:1000-1004.

8. Ander B P, Dupasquier C M, Prociuk M A, \& Pierce G N. Polyunsaturated fatty acids and their effects on cardiovascular disease.Exp Clin Cardiol, 2003, 8 (4), 164-172.

9. Calder P C. Mechanisms of Action of (n-3) Fatty Acids. The Journal of Nutrition, 2012. 592-599.

10. Raju M P, Babu D A, Kumar B R, \& Rajashekar C. The Role of Phytosterols Enriched Foods-A Review. Journal of Environmental Science, Toxicology and Food Technology, 7 (6), 2013, 40-47. 